\title{
Causes of mortality across different immigrant groups in northeastern Italy
}

Ugo Fedeli, Eliana Ferroni, Mara Pigato, Francesco Avossa, Mario Saugo

Background. Despite massive immigration towards Southern Europe in the last two decades, data on mortality by cause among immigrants in Italy are scarce. The aim of this study was to investigate mortality from all and from specific causes of death among immigrants residing in the Veneto Region (Northeastern Italy).

Methods. Mortality records for the period 2008-2013 were extracted from the regional archive of causes of death, whereas population data were obtained from the 2011 Italian census. Immigrants were grouped by area of provenience based on the information on country of citizenship available both in mortality and census data. Standardized Mortality Ratios (SMR) with 95\% Confidence Intervals (Cl) were computed for the period 2008-2013 in subjects aged 20-59 years, with rates of Italian citizens as a reference.

Results. Overall mortality was reduced both in male (SMR 0.86, $\mathrm{Cl} 0.80-0.92$ ) and female immigrants (SMR 0.72, Cl 0.65-0.78), although an increased risk was observed for subjects from Sub-Saharan Africa. Significantly raised SMR for circulatory diseases were found among Sub-Saharan Africans and Southern Asians in both genders. Sub-Saharan Africans experienced a higher risk of death especially from cerebrovascular diseases: SMR $4.78(\mathrm{Cl}$ 2.67-7.89) and SMR 6.09 (Cl 1.96-14.2) in males and females, respectively. Among Southern Asians the increase in mortality from ischemic heart diseases reached statistical significance in males (SMR 2.53, $\mathrm{Cl}$ 1.42-4.18). In spite of a lower risk of death for all neoplasms combined, mortality from cancer of cervix uteri was increased among immigrants (SMR 2.61, Cl 1.35-4.56), as well as for other cancer sites in selected immigrant groups. A raised mortality was found for infectious diseases in Sub-Saharan Africans (both genders), and for transport accidents among females from Eastern Europe.

Conclusion. Our study showed great variations in mortality by cause and area of provenience among immigrants resident in the Veneto Region and highlighted specific health issues that should be addressed through tailored efforts in chronic diseases prevention. 
2 Ugo Fedeli, Eliana Ferroni, Mara Pigato, Francesco Avossa, Mario Saugo

3

4

5 Epidemiological Department, Veneto Region, Italy

6 Passaggio Gaudenzio, 1 - 35131 Padova (PD), Italy

7

8

9

10

11 Corresponding author:

12 Ugo Fedeli

13 mail: ugo.fedeli@regione.veneto.it

14 Tel: +390498778251 Fax +390498778235

15

16

17 
19 Many studies have revealed the existence of mortality differences between the native and the immigrant population, with the latter usually showing lower rates due to many factors, mainly the "healthy migrant effect", observed both in North America and in European countries (Singh \& Hiatt, 2006; Spallek et al., 2012; Boulogne et al., 2012; Scott \& Timaeus, 2013; Omariba, Ng \& Vissandjée, 2014; Moncho et al., 2014). In fact, immigrants represent a much healthier population in many aspects than subjects who remain in their countries of origin and those in the host country (Regidor et al., 2008). However, mortality figures are undermined by large uncertainties in population estimates (denominators of rates) for immigrants. Furthermore, in some countries higher mortality rates in immigrants were observed, particularly in specific ethnic groups and for specific causes of death, with large variations observed by age and gender (Rostila \& Fritzell, 2014; Bos et al., 2007).

Literature on this issue in Italy is scarce, limited to studies investigating overall mortality or broad nosologic sectors, without distinguishing by area of provenience. In a previous report from Central Italy, mortality rates in immigrants coming from developing countries (all countries excluding North America, EU15, and a few other high-income countries) have been found to be halved with respect to the Italian population (Martini, Chellini \& Sala, 2011).

We aimed at reducing this information gap, providing detailed information on mortality in the immigrant population, taking advantage of both recent Italian census data with more reliable estimates of the residents by age, gender, and country of citizenship, and of updated mortality records coded according to the International Classification of Diseases, $10^{\text {th }}$ Edition (ICD-10).

\section{Methods}

\section{$\underline{\text { Study design and variable definition }}$}

4 This descriptive study compares all-cause and cause-specific mortality between Italian and legal 2 immigrants in the Veneto Region (Northeastern Italy). Mortality records were extracted from the 3 regional archive of causes of death, whereas population data were obtained from the 2011 Italian 4 Census (http://dati.istat.it/). 
46 Irregular immigrants (illegal entry or legal entry followed by overstay), as well as subjects with a shortterm stay in the region for tourism, study, or work were not included due to the lack of population (denominator) data. Since the immigrant population aged $\geq 64$ years is small, all analyses excluded elderly subjects. Furthermore, detailed comparisons between the Italian and immigrant population were restricted to residents aged 20-59 years to deal with a more homogeneous adult population.

\section{$51 \quad$ Setting}

52 Italy, traditionally a country of emigration, has experienced a large amount of immigration from 53 developing countries in the context of massive migrations toward Southern Europe in the last two 54 decades. Immigration in Italy is mainly for the purpose of working; in particular males from African 55 and South Asian countries are employed mainly in industry and construction, whereas females from 56 Eastern Europe are employed mainly in the care of elderly people. Another important reason for migration is family reunion. The contribution of asylum seekers has been increasing only in the more recent years. The Veneto Region (Northeastern Italy, about 5 million inhabitants) is a highly industrialized area, having one of the highest prevalence of foreign population in the country $(10 \%)$

60 due to many job opportunities available before the beginning of the recent economic crisis.

61

62 63

\section{$\underline{\text { Variables definition }}$}

Both the country of birth and the country of citizenship are registered in the death certificate. From the official census, population data are available only by country of citizenship. The latter variable was therefore utilized to define the immigrant (non-Italian) population. It must be remarked that immigrants can obtain Italian citizenship by marriage or -on demand- after a minimum of 10 consecutive years of legal residence. Their children can obtain it - if born in Italy - only after their $18^{\text {th }}$ birthday. Consequently in the present study the immigrant population also includes second generation immigrants (mostly limited to early pediatric age groups), and excludes subjects born abroad who acquired Italian citizenship as stated before. To deal with larger numbers, countries of citizenship were grouped by area of provenience based on macro-geographical regions and sub-regions defined by the United Nation Organization (Table 1).

(http://unstats.un.org/unsd/methods/m49/m49regin.htm) 


\section{$\underline{\text { Data collection }}$}

A copy of all death certificates in the Veneto Region is routinely transmitted to the Regional Epidemiology Department for coding of the causes of death. Since 2008, all diseases mentioned in the certificate are coded in ICD-10, and the selection of the underlying cause of death is performed using the ACME (Automated Classification of Medical Entities) software, downloaded from the US National Vital Statistics System website (http://www.cdc.gov/nchs/nvss/mmds.htm). Through the 2008-2013 period, satisfactory data quality is suggested by a low percentage $(6.6 \%)$ of deaths corresponding to unknown and ill-defined causes, as previously defined (Mathers et al., 2005): symptoms, signs and illdefined conditions (ICD-10 R00-R99), injuries with intent not determined (Y10-Y34), cardiovascular diseases with indefinite diagnostic meaning (I47.2, I49.0, I46, I50, I51.4, I51.5, I51.6; I51.9, I70.9), and cancer deaths from secondary, multiple, or unspecified sites (C76, C80, C97).

\section{$\underline{\text { Analysis }}$}

The regional mortality archive was investigated for the period 2008-2013 (2013 provisional data covering at least $98 \%$ of regional deaths), roughly centered around census data. Examined causes of death were the main classification chapters of the ICD-10 (infectious diseases, neoplasms, circulatory diseases, external causes). The most frequent disease categories were diabetes, cardiac ischemic diseases, cerebrovascular diseases, suicide, and transport accidents. Among tumors, those with larger numbers (lung, colorectal, breast), or with a priori knowledge of a possible increased risk among immigrants (stomach, liver, cervix uteri) were investigated. To properly compare populations (foreign and native) with huge differences in age structure, standardized mortality ratios (SMR) were computed as the ratios between deaths observed in the immigrant population (as a whole and for each area of provenience), and those expected according to age- and gender-specific mortality rates registered in Italian citizens. 95\% confidence intervals (CI) based on the Poisson distribution were obtained using the Byar's approximation (Breslow \& Day, 1987).

\section{Ethics}

The analysis of causes of mortality is included among mandatory activities of the Regional Epidemiology Department according to regional law. Data used in this study were completely anonymized; thus, ethical approval was deemed unnecessary. 


\section{Results}

103 Table 1 shows the age structure by gender of the study populations. The age distribution of immigrants

104 is heavily shifted towards younger age classes, being negligible the proportion of subjects aged $\geq 60$

105 years, except for the small group coming from more developed countries (EU15, US and other

106 countries). The largest immigrant group is constituted by subjects from Eastern Europe (more than

107 50\%), but also African countries (both Northern and Sub-Saharan) and Asian countries (both Southern

108 and other countries, mainly including China) are well represented.

109 In the period 2008-2013 there were 32,567 deaths in subjects aged $\leq 64$ years, 1,583 of which occurred

110 in immigrants (Figure 1). In Figure 2 it can be seen that mortality rates for all causes of death in

111 immigrants are higher in the pediatric population in both genders. Starting from the 20-24 year

112 (females) or the 30-34 year (males) age group, rates become higher among Italian citizens, with a

113 widening gap with increasing age, especially among females.

114 In analyses restricted to the 20-59 age interval, overall mortality in immigrants compared to that 115 observed among Italian citizens was $14 \%$ and $28 \%$ lower in males and females, respectively (Table 2).

116 The main causes of death among male immigrants were external causes, strictly followed by neoplasms

117 and circulatory diseases; among females, more than half of deaths were accounted for by neoplasms.

118 With respect to the native population, cancer mortality was decreased by about $30 \%$ in immigrants of 119 both genders (with larger decreases for colorectal and breast cancer), although a significant excess for

120 cervical cancer could be observed. Mortality from circulatory diseases, especially cerebrovascular

121 diseases, was increased in males, but not in females. Mortality from suicide was halved in both

122 genders, whereas that from road accidents was similar to the Italian population in males and increased

123 in females. Lastly, the excess risk for infectious diseases reached statistical significance among female

124 immigrants.

125 The mortality advantage observed among immigrants with respect to Italian citizens greatly varied by 126 area of provenience (Figure 3); in both genders, rates were significantly decreased among subjects 127 from North Africa and Eastern Europe, while they were raised among Sub-Saharan Africans (males

128 SMR 1.20, CI 1.01-1.41; females SMR 1.73, CI 1.30-2.26).

129 Table 3 shows variations in SMR for the leading causes of death by area of provenience (citizens from

130 South America and from other countries are not shown due to small numbers). High risks could be 
131 recognized for circulatory diseases among immigrants from Sub-Saharan Africa (especially

132 cerebrovascular diseases), and from South Asia (especially ischemic heart diseases), with an excess

133 mortality observed in both genders. Notably in the largest group (Eastern Europe), mortality from

134 circulatory diseases was decreased in females but not in males, which contributes to the gender gap in

135 SMR estimates for circulatory disorders computed for the whole immigrant population. Overall cancer

136 mortality was decreased among almost all immigrant groups, but specific excess risks could be

137 detected for liver cancer (Asian countries, Sub-Saharan Africa), lung cancer (Asian countries, Eastern

138 Europe with borderline significance), and cancer of the cervix uteri (Eastern Europe). Lastly the

139 increase in mortality from infectious diseases was limited to subjects from Sub-Saharan Africa, and the

140 increase in fatal transport accidents in females was confirmed in the largest immigrant group (Eastern

141 Europe).

142

\section{Discussion}

144 The present study demonstrates a great variation in mortality risk among immigrants in Italy by age, 145 gender, area of provenience and specific cause of death. Overall, immigrants aged 20-59 years showed 146 a lower mortality risk compared to Italian citizens, but this advantage (less than 15\% among males and $14730 \%$ among females) is smaller than what was previously found in an earlier study from another Italian 148 region (Martini, Chellini \& Sala, 2011), and similar to reports from the US and Western Europe (Singh 149 \& Hiatt, 2006; Scott \& Timaeus, 2013). In particular, the increased risk of total mortality in Sub150 Saharan Africans confirms data from Spain (Regidor et al., 2009) and England (Wild et al., 2007). In 151 analyses of specific causes of death, the increased mortality for cervical cancer and the reduced 152 mortality for breast and colorectal cancer is in line with the results of studies carried out in Sweden

153 (Abdoli, Bottai \& Morandi, 2014) and in other European countries (Arnold, Razum \& Coebergh, 154 2010), but also with the scarce data available on cancer incidence among immigrants in Italy 155 (Manneschi et al., 2011). For cervical cancer, screening practices (Zorzi et al., 2014) and factors 156 affecting the access to cancer treatment may be different among immigrant women, leading to a higher 157 mortality rate. Nonetheless, the increased mortality found among selected immigrant groups for cancer 158 sites with low survival rates suggests that exposure to specific risk factors, rather than delayed 159 diagnosis or worse cancer care could play a major role, such as for liver cancer (exposure to hepatitis B

160 virus and to aflatoxin) and for lung cancer (smoking habits). The higher risk of circulatory diseases in 
161 Sub-Saharan Africans and South Asians, which has already been reported in England (Wild et al.,

162 2007) and Spain (Regidor et al., 2009), could be explained by the high prevalence of hypertension and 163 diabetes in these two regions (Misra et al., 2014; Soni Raleigh 1997; Cappucio et al., 1997; Yoon et al., 164 2006). Therefore, it becomes very important from a public health perspective to monitor such specific 165 risk profiles, e.g. for better surveillance and control of blood pressure. This can help policy-makers to 166 develop priorities for primary and secondary prevention. For example, for circulatory disorders, 167 physical activity and a healthy diet should be promoted, and known risk factors (hypertension, 168 diabetes) should be better controlled at a primary care level; for cancer, participation in cervical cancer 169 screening programs should be increased, and anti-smoking campaigns should be reinforced and tailored 170 towards ethnic groups at a higher risk.

171 The mortality ratio between the immigrant and the Italian population greatly varies with age. We found 172 an increased mortality among immigrant children, especially in the youngest age class (0-4 years). An 173 increased infant mortality rate among immigrants is a well-known phenomenon in Italy (Martini, 174 Chellini \& Sala, 2011). Previous studies have shown that infant mortality rates depend on the 175 immigrant's destination country, and that different effects are associated with different source countries 176 (Naimy et al., 2013). In Italy, as in other Western countries, an increasing proportion of births are from 177 immigrant women coming from world regions where low birth weight and infant death are more 178 frequent (Sobotka 2008).

179 The risk of death remains higher through all pediatric age classes (females) and also in young adults 180 (males). Thereafter, the mortality gap favorable to immigrants becomes larger with age. This pattern 181 has already been reported in the Netherlands (Bos et al., 2007), with a similar definition of the 182 immigrant population (including second-generation immigrants). Moreover, the underestimation of 183 mortality rates among immigrants has been reported to be more probable in older age classes, mainly 184 due to unregistered remigration to the country of origin (Spallek et al., 2012). Within this scenario, all 185 methods of age-standardization are inadequate, leading to different rate ratios when applying different 186 standards. Therefore, we chose to truncate estimates at 59 years of age. We decided also to exclude 187 from the analysis the pediatric population based on two main reasons: causes of death (mainly 188 perinatal and congenital causes in ICD-10) are usually specific and non-comparable with the adult 189 population, and available data on mortality from cancer and circulatory diseases among immigrants in 190 Europe are generally restricted to the adult population. Furthermore, through indirect standardization, 
191 weights were chosen from the study (immigrant) populations, and SMR estimates allowed to explore 192 cause-specific mortality rate ratios across different immigrant groups also when dealing with small 193 numbers.

194 As the census takes place only every 10 years, restricting the analysis of mortality to years close to the 195 census helped to deal with reliable denominators for mortality rates (Wild et al., 2007). The use of 196 census data could have introduced a numerator/denominator bias. However, this bias should be of 197 limited size in analyses by large area of provenience and not by single country of citizenship (Regidor 198 et al., 2008). In particular, the use of census data allows to limit the magnitude of some biases that

199

200

201

202

203

204 usually lead to an underestimation of mortality in immigrants, namely the mobility bias (immigrants spend shorter or longer periods in the country of origin), and unregistered remigration (delays in registration in municipal registries of the final return to the country of origin), which usually inflate the mortality rate denominators. In particular, the remigration can be differential, affecting especially immigrants with health problems and/or low socio-economic profiles (unhealthy remigration effect). Furthermore, during periods of global economic crisis, both remigration to the country of origin and a new emigration towards other countries with more job opportunities may increase.

We excluded from our analyses immigrants who are not residents but are legally present in the study area, as well as illegal immigrants. These subjects are estimated to account for another 10-15\% of the immigrant population in Italy (Blangiardo 2013). Due to the lack of estimates by age, gender or area of provenience, the study was restricted to legal residents.

One limitation of the study is the absence of data on socioeconomic status and on time since immigration. Some studies found death rates to be substantially influenced by socio-economic status in immigrants (Bos et al., 2004, Rostilla et al., 2014, Abdoli et al., 2014), and socio-economic inequalities are considered a sizeable cause of inequalities in mortality by country of origin.

The length of time of residence in the host country is assumed to be a proxy for acculturation; at the same time, it could be expected that with time spent in the host country, immigrant groups increasingly assume specific risk patterns of the native population. Such changes are difficult to predict in the presence of rapidly changing dynamic populations (Bos et al., 2004): new subjects undergoing selective immigration patterns continue to contribute to the growth of immigrant groups; moreover, the global process of westernization of dietary habits and other risk factors is heavily involving most 
220 emigration countries, and many young adults coming to Europe have probably already acquired risk

221 profiles associated with nutritional habits and metabolic attributes in their country of origin (Misra \& 222 Ganda, 2007). To address the transition of mortality patterns, it would be necessary to compare 223 mortality figures also with those of the countries of origin; however only few previous studies were 224 able to collect relevant data to investigate this issue (Spallek et al., 2012). Furthermore, it should be 225 taken into account that the health status of different populations of immigrants could depend on 226 differences not only in the exposure to risk factors in their country of origin, but also in reasons for 227 migration and migration pathways due to geographical distance or other barriers.

228 Within this context, surveillance of mortality by cause is of paramount importance to set priorities for 229 both research and public health. The present data reduces the informative gap on mortality among immigrants in Italy, highlighting the need for further analyses at both the regional and national levels.

\section{Conclusion}

233 Our results have shown important variations in mortality by area of provenience, in most cases similar 234 to what has been reported in studies performed in traditional immigration countries of North America 235 and other parts of Europe. Specifically, mortality from circulatory diseases emerges as a public health 236 concern, especially in selected immigrant groups. These data support a recent multidisciplinary call for 237 more detailed data on cardiovascular risk factors aimed at a better control of circulatory diseases 238 among immigrants in Italy (Modesti et al., 2014). A continual monitoring of immigrants' health is 239 crucial since its improvement will have a substantial impact on the population's overall health and on 240 the magnitude of health inequalities (Singh et al., 2006).

\section{References}

1. Abdoli G, Bottai M, Moradi T. 2014. Cancer mortality by country of birth, sex, and socioeconomic position in Sweden, 1961-2009. PLoS One 9:e93174.

2. Arnold M, Razum O, Coebergh JW. 2010. Cancer risk diversity in non-western migrants to 246 Europe: An overview of the literature. Eur J Cancer 46:2647-2659. 
3. Blangiardo GC. Stima delle presenze irregolari. Capitolo estratto da Diciottesimo Rapporto sulle migrazioni 2012, Franco Angeli, Milano, 2013.

4. Bos V, Kunst AE, Keij-Deerenberg IM, Garssen J, Mackenbach JP. 2004. Ethnic inequalities in age- and cause-specific mortality in The Netherlands. Int J Epidemiol 33:1112-1119.

5. Bos V, Kunst AE, Garssen J, Mackenbach JP. 2007. Duration of residence was not consistently related to immigrant mortality. J Clin Epidemiol 60:585-592.

6. Boulogne R, Jougla E, Breem Y, Kunst AE, Rey G. 2012. Mortality differences between the foreign-born and locally-born population in France (2004-2007). Soc Sci Med 74:1213-1223.

7. Breslow NE, Day NE. 1987. Statistical Methods in Cancer Research, Volume II: The Design and Analysis of Cohort Studies. New York: Oxford University Press.

8. Cappucio FP, Cook DG, Atkinson RW, Strazzullo P. Prevalence, detection, and management of cardiovascular risk factors in south London. Heart. 1997;78:555-63.

9. Manneschi G, Crocetti E, Puliti D, Zappa M, Sacchettini C, Paci E. 2011. Cancer incidence in Italian natives and in first-generation immigrants to Italy. Epidemiol Prev 35:292-296.

10. Martini A, Chellini E, Sala A. 2011. Mortality in immigrants in Tuscany. Epidemiol Prev 35:275281.

11. Mathers CD, Fat DM, Inoue M, Rao C, Lopez AD. Counting the dead and what they died from: an assessment of the global status of cause of death data. Bull World Health Organ 2005;83:171-177.

12. Misra A, Ganda OP. 2007. Migration and its impact on adiposity and type 2 diabetes. Nutrition 23:696-708.

13. Misra A, Ramchandran A, Jayawardena R, Shrivastava U, Snehalatha C. 2014. Diabetes in South Asians. Diabet Med 31:1153-1162.

14. Modesti PA, Bianchi S, Borghi C, Cameli M, Capasso G, Ceriello A, Ciccone MM, Germanò G, Maiello M, Muiesan ML, Novo S, Padeletti L, Palmiero P, Pillon S, Rotella CM, Saba PS, Scicchitano P, Trimarco B, Volpe M, Pedrinelli R, Di Biase M. 2014. Cardiovascular health in migrants: current status and issues for prevention. A collaborative multidisciplinary task force report. J Cardiovasc Med 15:683-692.

15. Moncho J, Pereyra-Zamora P, Nolasco A, Tamayo-Fonseca N, Melchor I, Macia L. 2014. Trends and Disparities in Mortality Among Spanish-Born and Foreign-Born Populations Residing in Spain, 1999-2008. J Immigr Minor Health 2014 Jul 26. [Epub ahead of print] 
277

278

279

280

281

282

283

284

285

286

287

288

289

290

291

292

293

294

295

296

297

298

299

300

301

302

303

304

305

306

16. Naimy, Z., Grytten, J., Monkerud, L., and Eskild, A. (2013). Perinatal mortality in nonwestern migrants in Norway compared to their countries of birth and to Norwegian women. BMC Public Health 13(1): 37.

17. Omariba DW, Ng E, Vissandjée B. 2014. Differences between immigrants at various durations of residence and host population in all-cause mortality, Canada 1991-2006. Popul Stud 68:339-357.

18. Regidor E, de La Fuente L, Martínez D, Calle ME, Domínguez V. 2008. Heterogeneity in causespecific mortality according to birthplace in immigrant men residing in Madrid, Spain. Ann Epidemiol 18:605-613.

19. Regidor E, Astasio P, Calle ME, Martínez D, Ortega P, Domínguez V. 2009. The association between birthplace in different regions of the world and cardiovascular mortality among residents of Spain. Eur J Epidemiol 24:503-512.

20. Rostila M, Fritzell J. 2014. Mortality differentials by immigrant groups in Sweden: the contribution of socioeconomic position. Am J Public Health 104:686-695.

21. Scott AP Timaeus IM. 2013. Mortality differentials 1991-2005 by self-reported ethnicity: findings from the ONS Longitudinal Study. J Epidemiol Community Health 67:743-750.

22. Singh GK, Hiatt RA. 2006. Trends and disparities in socioeconomic and behavioural characteristics, life expectancy, and cause-specific mortality of native-born and foreign-born populations in the United States, 1979-2003. Int J Epidemiol 35:903-919.

23. Sobotka T. Overview chapter 7: the rising importance of migrants for childbearing in Europe. Demogr Res 2008;19article 9:225-248.

24. Soni Raleigh V. Diabetes and hypertension in Britain's ethnic minorities: implications for the future of renal services. BMJ. 1997;314:209-13

25. Spallek J, Arnold M, Razum O, Juel K, Rey G, Deboosere P, Mackenbach JP, Kunst AE. 2012. Cancer mortality patterns among Turkish immigrants in four European countries and in Turkey. Eur J Epidemiol 27:915-921.

26. Wild SH, Fischbacher C, Brock A, Griffiths C, Bhopal R. 2007. Mortality from all causes and circulatory disease by country of birth in England and Wales 2001-2003. J Public Health 29:191198.

27. Yoon K-H, Lee J-H, Jim J-W, Cho JH, Choi Y-H, Ko S-H, et al. Epidemic obesity and type 2 diabetes in Asia. Lancet. 2006;368: 1681-8 
307 28. Zorzi M, Fedato C, Cogo C, Baracco S, Turrin A. 2014. I programmi di screening oncologici del 308 Veneto. Rapporto 2012-2013. 


\section{Table 1 (on next page)}

Study populations

Distribution of residents in the Veneto Region by gender, age group, and citizenship: 2011 census. 
2 Table 1. Distribution of residents in the Veneto Region by gender, age group, and citizenship: 2011 census.

\begin{tabular}{|c|c|c|c|c|c|c|c|c|c|}
\hline & Italians & $\begin{array}{l}\text { All } \\
\text { immigrants }\end{array}$ & $\begin{array}{l}\text { North } \\
\text { Africa }\end{array}$ & $\begin{array}{l}\text { Sub- } \\
\text { Saharan } \\
\text { Africa }\end{array}$ & $\begin{array}{l}\text { South } \\
\text { Asia }\end{array}$ & $\begin{array}{l}\text { Other } \\
\text { Asian } \\
\text { countries }\end{array}$ & $\begin{array}{l}\text { Central } \\
\text { and South } \\
\text { America }\end{array}$ & $\begin{array}{l}\text { Eastern } \\
\text { Europe }\end{array}$ & $\begin{array}{l}\text { Other } \\
\text { countries\# }\end{array}$ \\
\hline Males, $\mathrm{n}$ & $2,144,204$ & $220,478^{*}$ & 33,276 & 24,713 & 25,095 & 16,730 & 5,286 & 111,068 & 4,295 \\
\hline \multicolumn{10}{|c|}{ Males, age distribution (\%) } \\
\hline $0-19$ yrs & $19 \%$ & $30 \%$ & $33 \%$ & $30 \%$ & $29 \%$ & $34 \%$ & $27 \%$ & $30 \%$ & $14 \%$ \\
\hline $20-59$ yrs & $55 \%$ & $67 \%$ & $64 \%$ & $69 \%$ & $70 \%$ & $64 \%$ & $71 \%$ & $68 \%$ & $64 \%$ \\
\hline$\geq 60$ yrs & $26 \%$ & $2 \%$ & $3 \%$ & $1 \%$ & $1 \%$ & $2 \%$ & $3 \%$ & $2 \%$ & $22 \%$ \\
\hline Females, $\mathrm{n}$ & $2,255,678$ & $236,850 *$ & 27,841 & 17,944 & 17,977 & 17,460 & 10,235 & 138,555 & 6,828 \\
\hline \multicolumn{10}{|c|}{ Females, age distribution (\%) } \\
\hline $0-19$ yrs & $17 \%$ & $26 \%$ & $37 \%$ & $38 \%$ & $35 \%$ & $30 \%$ & $13 \%$ & $22 \%$ & $8 \%$ \\
\hline $20-59$ yrs & $51 \%$ & $70 \%$ & $58 \%$ & $61 \%$ & $63 \%$ & $68 \%$ & $82 \%$ & $74 \%$ & $78 \%$ \\
\hline$\geq 60 \mathrm{yrs}$ & $32 \%$ & $4 \%$ & $4 \%$ & $1 \%$ & $2 \%$ & $2 \%$ & $5 \%$ & $4 \%$ & $14 \%$ \\
\hline
\end{tabular}

3 *Including 15 male and 10 female stateless subjects

4 \#Other countries: EU15, US, Canada, Australia, New Zealand, Israel, Japan, South Korea, Iceland, Liechtenstein, Norway, San Marino,

5 Switzerland 


\section{Table 2 (on next page)}

SMR in immigrant vs. Italian citizens

Standardized mortality ratios (SMR) with 95\% Confidence Intervals (CI) in immigrants aged 20-59 years with respect to Italian citizens. Veneto Region, 2008-2013. Significantly increased SMR in bold. 
2 Table 2. Standardized mortality ratios (SMR) with 95\% Confidence Intervals (CI) in immigrants aged 3 20-59 years with respect to Italian citizens. Veneto Region, 2008-2013. Significantly increased SMR in 4 bold.

\begin{tabular}{|c|c|c|c|c|}
\hline Cause of death (ICD-10 codes) & Males & & Females & \\
\hline & $\mathbf{n}$ & $\operatorname{SMR}(\mathrm{CI})$ & n & SMR (CI) \\
\hline All causes & 863 & $0.86(0.80-0.92)$ & 466 & $0.72(0.65-0.78)$ \\
\hline Infectious diseases (A01-B99) & 41 & $1.18(0.85-1.60)$ & 25 & $1.64(1.06-2.42)$ \\
\hline All neoplasms (C00-D48) & 229 & $0.71(0.62-0.80)$ & 258 & $0.68(0.60-0.76)$ \\
\hline \multicolumn{5}{|l|}{ Malignant neoplasm of: } \\
\hline Stomach (C16) & 16 & $0.98(0.56-1.59)$ & 16 & $1.04(0.60-1.70)$ \\
\hline Colon, rectum and anus (C18-C21) & 13 & $0.38(0.20-0.66)$ & 15 & $0.43(0.24-0.71)$ \\
\hline Liver and intrahepatic bile ducts (C22) & 26 & $1.11(0.73-1.63)$ & 5 & $0.65(0.21-1.51)$ \\
\hline Trachea, bronchus and lung (C33-C34) & 64 & $1.15(0.89-1.47)$ & 31 & $0.73(0.49-1.03)$ \\
\hline Female breast (C50) & & & 59 & $0.58(0.44-0.74)$ \\
\hline Cervix uteri (C53) & & & 12 & $2.61(1.35-4.56)$ \\
\hline Corpus and uterus n.s. (C54-C55) & & & 14 & $1.12(0.61-1.88)$ \\
\hline Diabetes (E10-E14) & 12 & $0.93(0.48-1.63)$ & 7 & $1.32(0.53-2.71)$ \\
\hline All circulatory diseases (I00-I99) & 188 & $1.13(0.97-1.30)$ & 48 & $0.73(0.54-0.97)$ \\
\hline Ischaemic heart diseases (I20-I25) & 71 & $1.01(0.79-1.27)$ & 12 & $0.71(0.36-1.23)$ \\
\hline Cerebrovascular diseases (I60-I69) & 36 & $1.43(1.00-1.98)$ & 17 & $0.93(0.54-1.50)$ \\
\hline All external causes (V01-Y89) & 275 & $0.91(0.80-1.02)$ & 77 & $0.95(0.75-1.19)$ \\
\hline Transport accidents (V01-V99) & 133 & $1.00(0.83-1.18)$ & 40 & $1.41(1.01-1.92)$ \\
\hline Suicide (X60-X84) & 55 & $0.50(0.38-0.66)$ & 19 & $0.53(0.32-0.83)$ \\
\hline
\end{tabular}




\section{Table 3(on next page)}

SMR by area of provenience

Standardized mortality ratios with $95 \%$ Confidence intervals in immigrants aged $20-59$ years with respect to Italian citizens, by area of provenience and gender ( $M=$ males, $F=$ females). Veneto Region, 2008-2013. Significantly increased SMR in bold. 
2 Table 3. Standardized mortality ratios with 95\% Confidence intervals in immigrants aged 20-59 years with respect to Italian citizens, by

3 area of provenience and gender ( $\mathrm{M}=$ males, $\mathrm{F}=$ females). Veneto Region, 2008-2013. Significantly increased SMR in bold.

\begin{tabular}{|c|c|c|c|c|c|c|}
\hline & & North Africa & Sub-Saharan Africa & South Asia & Asia, other & Eastern Europe \\
\hline \multirow[t]{2}{*}{ Infectious diseases } & $\mathrm{M}$ & $0.75(0.20-1.91)$ & $4.35(2.65-6.71)$ & $1.53(0.49-3.57)$ & $1.14(0.23-3.33)$ & $0.41(0.16-0.85)$ \\
\hline & $\mathrm{F}$ & $1.68(0.19-6.05)$ & $11.5(5.23-21.8)$ & $1.34(0.02-7.46)$ & $0.96(0.01-5.35)$ & $1.19(0.62-2.09)$ \\
\hline \multirow[t]{2}{*}{ All neoplasms } & M & $0.61(0.41-0.87)$ & $0.72(0.48-1.03)$ & $0.36(0.17-0.65)$ & $0.89(0.55-1.36)$ & $0.76(0.63-0.90)$ \\
\hline & $\mathrm{F}$ & $0.49(0.27-0.82)$ & $0.91(0.51-1.50)$ & $0.81(0.44-1.36)$ & $0.74(0.44-1.17)$ & $0.64(0.55-0.75)$ \\
\hline \multirow[t]{2}{*}{ Liver cancer } & M & $0.57(0.06-2.04)$ & $3.05(1.39-5.79)$ & $1.09(0.12-3.94)$ & $3.53(1.29-7.68)$ & $0.51(0.18-1.10)$ \\
\hline & $\mathrm{F}$ & $1.66(0.02-9.23)$ & & & $4.08(0.46-14.7)$ & $0.38(0.04-1.38)$ \\
\hline \multirow[t]{2}{*}{ Lung cancer } & M & $0.60(0.19-1.39)$ & $1.03(0.41-2.11)$ & & $2.26(1.03-4.29)$ & $1.38(0.98-1.88)$ \\
\hline & $\mathrm{F}$ & $0.34(0.00-1.89)$ & & $0.60(0.01-3.36)$ & $0.40(0.01-2.25)$ & $0.79(0.51-1.18)$ \\
\hline Cervix uteri cancer & $\mathrm{F}$ & & $8.13(0.91-29.4)$ & $4.22(0.06-23.50)$ & $3.08(0.04-17.12)$ & $2.67(1.15-5.26)$ \\
\hline \multirow[t]{2}{*}{ Circulatory diseases } & $\mathrm{M}$ & $0.83(0.51-1.27)$ & $2.16(1.58-2.89)$ & $1.67(1.08-2.47)$ & $1.06(0.57-1.82)$ & $0.94(0.74-1.17)$ \\
\hline & $\mathrm{F}$ & $1.00(0.32-2.32)$ & $3.39(1.62-6.24)$ & $2.61(1.12-5.14)$ & $0.48(0.05-1.72)$ & $0.45(0.28-0.70)$ \\
\hline \multirow[t]{2}{*}{ Ischemic heart } & M & $0.56(0.20-1.22)$ & $1.10(0.53-2.03)$ & $2.53(1.42-4.18)$ & $1.36(0.54-2.80)$ & $0.85(0.58-1.22)$ \\
\hline & $\mathrm{F}$ & & $1.57(0.02-8.71)$ & $4.33(0.87-12.66)$ & & $0.59(0.24-1.21)$ \\
\hline \multirow[t]{2}{*}{ Cerebrovascular } & $M$ & $0.78(0.16-2.29)$ & $4.78(2.67-7.89)$ & $1.29(0.26-3.77)$ & $2.18(0.59-5.57)$ & $0.87(0.44-1.56)$ \\
\hline & $\mathrm{F}$ & $1.43(0.16-5.15)$ & $6.09(1.96-14.2)$ & $2.31(0.26-8.35)$ & $1.69(0.19-6.12)$ & $0.49(0.18-1.06)$ \\
\hline \multirow[t]{2}{*}{ External causes } & $\mathrm{M}$ & $1.04(0.76-1.39)$ & $0.69(0.44-1.03)$ & $0.74(0.48-1.08)$ & $0.78(0.45-1.24)$ & $0.94(0.80-1.11)$ \\
\hline & $\mathrm{F}$ & $0.65(0.21-1.51)$ & $0.96(0.31-2.24)$ & $0.56(0.11-1.64)$ & $0.52(0.10-1.52)$ & $0.97(0.72-1.29)$ \\
\hline \multirow[t]{2}{*}{ Transport accidents } & M & $1.29(0.83-1.92)$ & $0.68(0.32-1.25)$ & $0.75(0.39-1.32)$ & $0.62(0.23-1.36)$ & $1.06(0.83-1.33)$ \\
\hline & $\mathrm{F}$ & $0.34(0.00-1.88)$ & $1.06(0.12-3.81)$ & $0.47(0.01-2.63)$ & $1.01(0.11-3.66)$ & $1.63(1.08-2.35)$ \\
\hline
\end{tabular}

4 


\section{1}

\section{Selection of mortality records}

Figure 1 - Selection of deaths of residents in the Veneto Region by age and country of citizenship, 2008-2013

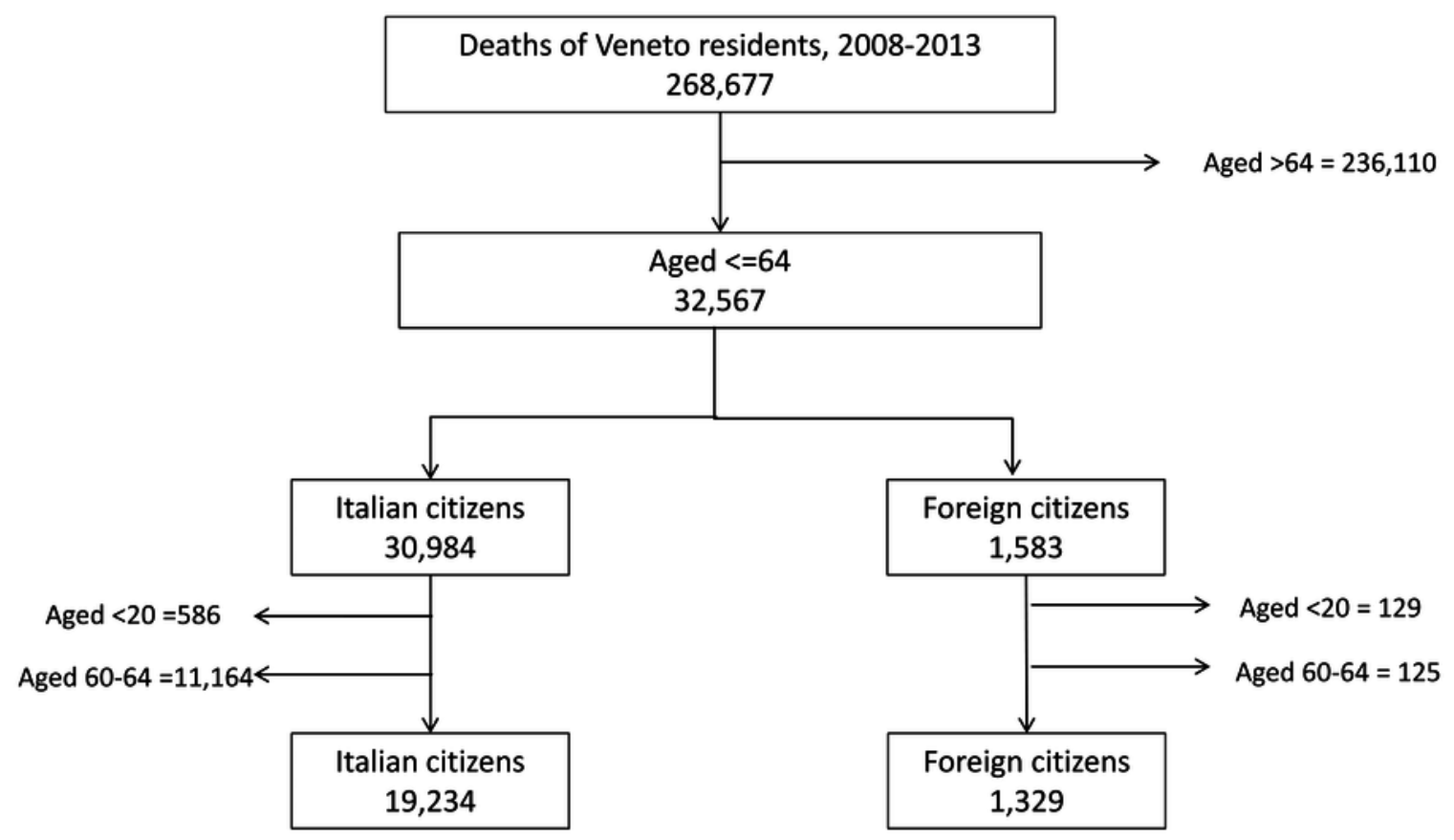


2

Overall mortality rates

Figure 2 - Age-specific mortality rates (x100,000) by gender in Italian and foreign citizens. Veneto Region, 2008-2013.

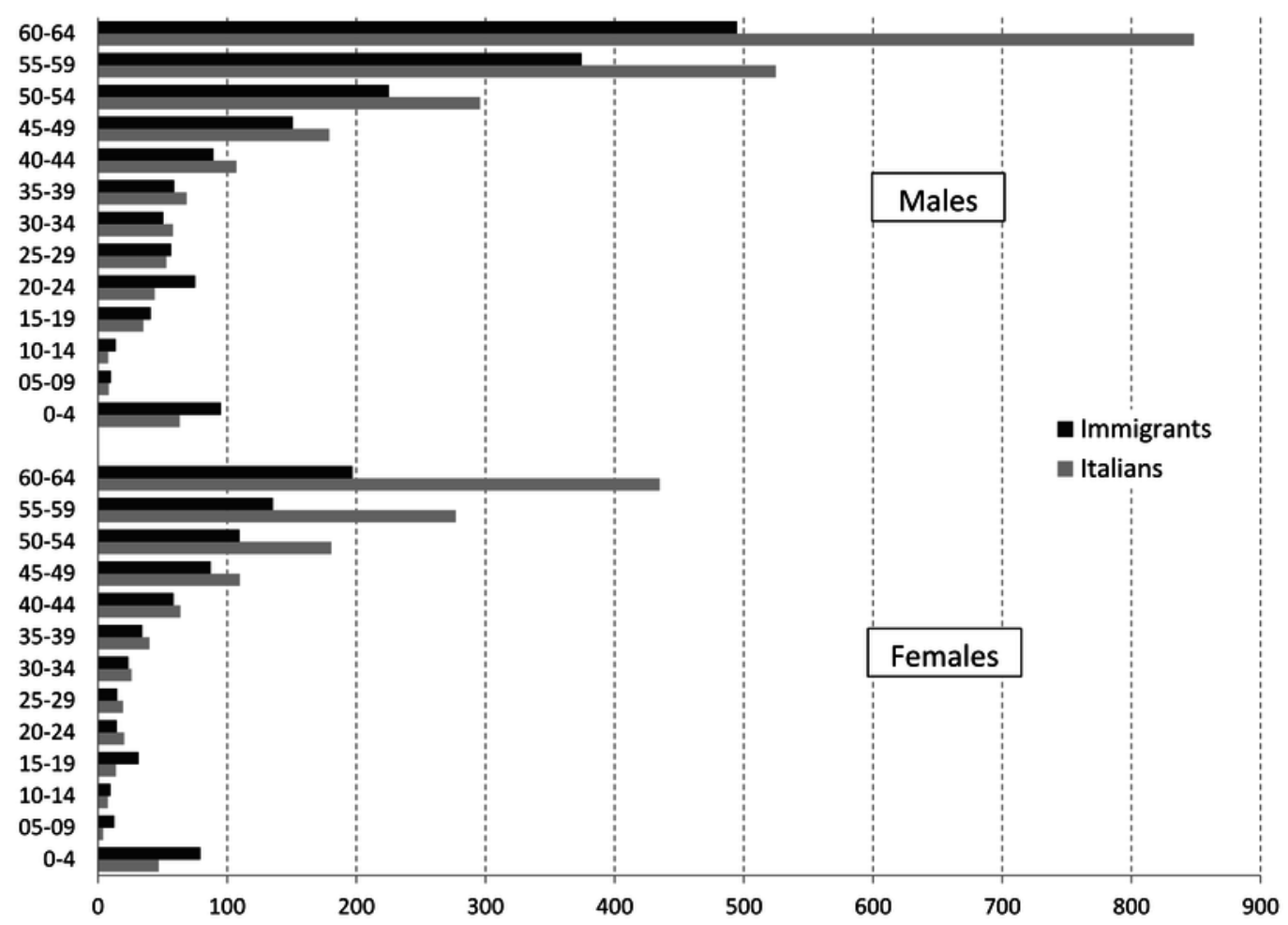


3

SMR by area of provenience

Figure 3 - Standardized mortality ratios (SMR) with 95\% Confidence Intervals (CI) for all causes of death in immigrants aged 20-59 years with respect to Italian citizens (SMR=1.00), by area of provenience and gender. Veneto Region, 2008-2013. 

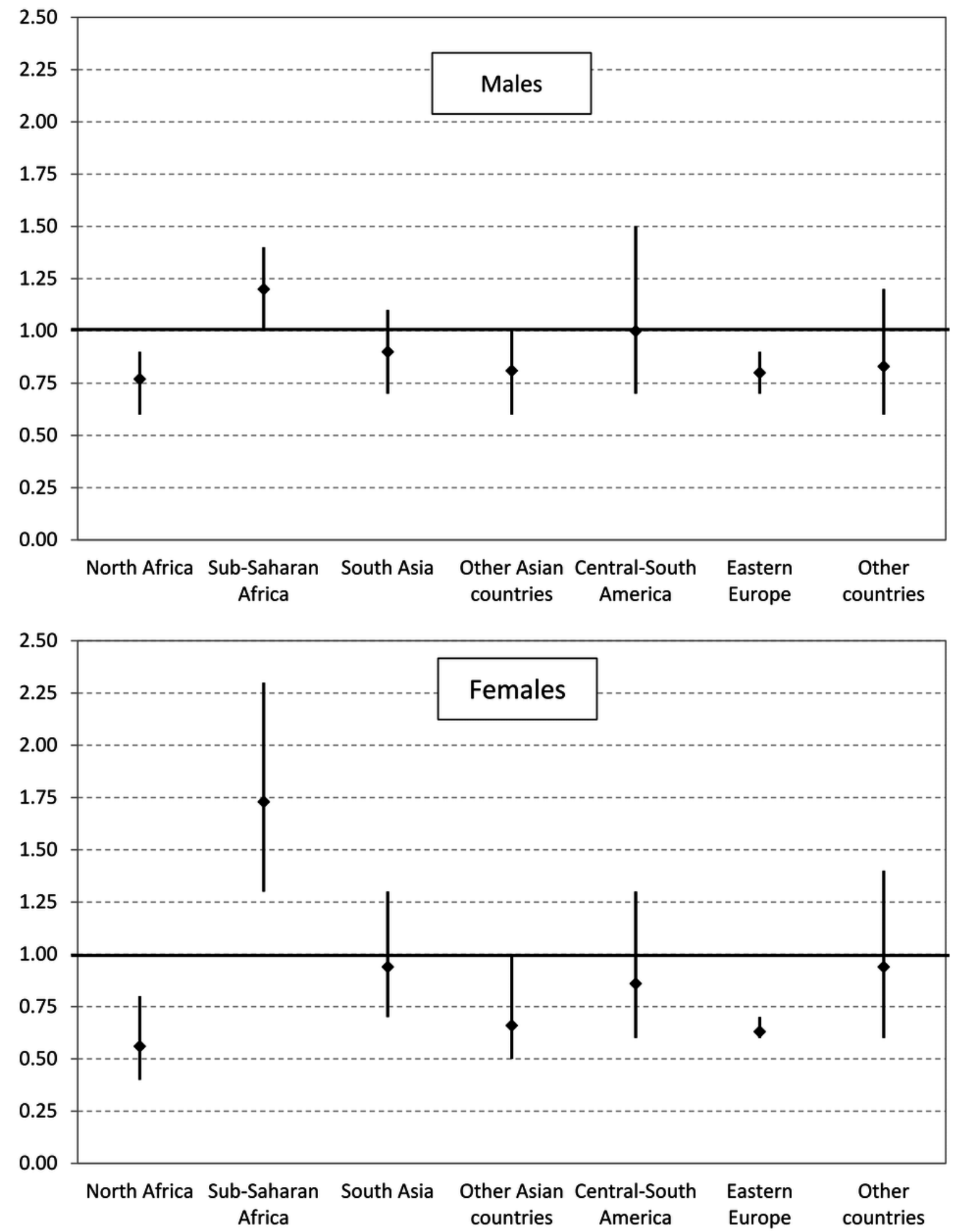